\title{
Novel air sterilization process for clean air production and microbial spread limitation using protection devices
}

\author{
Jean Claude Assaf ${ }^{1,3,4,5,6, *}$, Régina Geitani ${ }^{2}$, Dolla Karam Sarkis ${ }^{2}$, Richard Maroun ${ }^{1}$ \\ and Nicolas Louka ${ }^{1}$ \\ ${ }^{1}$ Centre d'Analyses et de Recherche (CAR), Unité de Recherche Technologies et \\ Valorisation agro-Alimentaire (UR-TVA), Faculté des Sciences, Université Saint-Joseph de \\ Beyrouth, Campus des sciences et technologies, Mar Roukos, Matn, Liban \\ ${ }^{2}$ Laboratoire des agents pathogènes, Faculté de pharmacie, Université Saint-Joseph de \\ Beyrouth, Campus des sciences médicales, Riad El Solh, Liban \\ ${ }^{3}$ Chemical Engineering Laboratory, Department of Chemical and Petrochemical Engineering, \\ Faculty of Engineering, Lebanese University, Lebanon \\ ${ }^{4}$ Chemical Engineering Laboratory, Department of Chemical and Petrochemical Engineering, \\ Faculty of Engineering (ESIB), Saint Joseph University, Mar Roukos, Matn, Lebanon \\ ${ }^{5}$ Research Laboratory of Microbiology, Department of Life and Earth Sciences, Faculty of \\ Sciences I, Lebanese University, Hadat Campus, Beirut, Lebanon \\ ${ }^{6}$ Department of Chemical Engineering, Faculty of Engineering, University of Balamand, \\ Koura, Lebanon \\ *Corresponding author: Jean Claude Assaf \\ E-mail address: jeanclaude.assaf@net.usj.edu.lb
}

\begin{abstract}
This work aims to develop and simulate a novel process based on sterilizing natural air by heating at high temperatures followed by rapid cooling. The new sustainable process is called "Air Rapid Heating Rapid Cooling Sterilization" (ARHRCS). Thus, it can be used in Heating, Ventilation, and Air Conditioning (HVAC) systems in hospitals to produce safe air, free of pathogenic airborne microbes including bacteria and viruses such as tuberculosis (TB) and coronavirus (SARS-CoV-2). A crown fixed on the head of the medical staff may be connected to the HVAC system to produce a constant flow of clean laminar air. Hence, this crown is capable of keeping airborne microorganisms at a safe distance from Health Care Workers (HCWs), avoiding any potential microbial infection. Accordingly, HCWs will be able to work in more suitable and safe conditions, especially in high infection risk areas. Depending on its need, the newly developed process may be implemented in different other locations such as laboratories, malls, buildings, and other crowded spaces. Further applications of this method may arise including its usage in the sterilization of recirculated air in biosafety cabinets and the development of a portable air sterilizing unit.
\end{abstract}

Keywords: Air sterilization; HVAC system; Process simulation; Hospital wards; Microbial spread. 


\section{INTRODUCTION}

Various clinically airborne diseases are caused by pathogenic microorganisms such as viruses, bacteria, and fungi (Fernstrom and Goldblatt 2013). Some of these airborne transmitted pathogens include, but are not limited to, coronavirus (e.g., SARS, MERS and novel SARSCoV-2), Influenza A virus (H1N1), tuberculosis (TB), and streptococcus pneumoniae (Tang et al. 2006). Hence, their route of transmission may be through coughing, sneezing, speaking, or any other activity that results in the spread of these infectious agents. It is worth noting that regarding coronavirus disease (COVID-19) pandemic, the world health organization (WHO) issued a scientific brief on SARS-CoV-2 viral airborne transmission via aerosols $(<5 \mu \mathrm{m}$ diameter) indicating a possible implications of such a route of transmission (WHO 2020). The respiratory droplets ( $>5 \mu \mathrm{m}$ diameter) remains the predominant transmission route of SARS$\mathrm{CoV}-2$. Airborne transmission in healthcare facilities is a matter of main importance for public, media and governments around the globe, especially when unacceptable levels of morbidity and mortality are reached.

The Heating, Ventilation, and Air Conditioning (HVAC) system provides quality air and comfort for HCWs, patients, and visitors in hospitals. The air quality is maintained by using specific air filters and comfort by controlling temperature, airflow, and humidity levels (Air indoor 2000). The basic equipment of an HVAC system includes ventilation equipment (fans), air filters, heating, and cooling coils, humidification, and dehumidification equipment (Air indoor 2000). The heating and cooling system is used to regulate and maintain an appropriate room air temperature. HVAC system in hospital wards is of prime importance and can be playing a dual role even by limiting the spread of the microorganism in the medical establishment or by facilitating its spread in the environment (WHO 2020; Vijayan et al. 2015).

It is worthy to mention that most microorganisms are sensitive to heat and can be inactivated at varying temperatures including, TB $\left(80{ }^{\circ} \mathrm{C}, 20 \mathrm{~min}\right), \mathrm{H} 1 \mathrm{~N} 1\left(70{ }^{\circ} \mathrm{C}, 14 \mathrm{sec}.\right)$, SARS-CoV-2 (92 ${ }^{\circ} \mathrm{C}, 15 \mathrm{~min}$ ) (Firquet et al. 2014; Sabiiti et al. 2019; Pastorino et al. 2020). The air incubation time may be greatly reduced to few seconds when the temperature is highly increased $\left(>100^{\circ} \mathrm{C}\right)$ (Firquet et al. 2014).

This work aims to simulate a safe and sustainable process capable of sterilizing natural air from the spread of pathogenic microbes inside hospital wards and other enclosed spaces with various potential applications. Consequently, improving the working conditions and safety of patients, HCWs, and humans well-being. Moreover, after the failure of advanced air filtration technologies in providing an efficient system with low maintenance costs and unceasing high performance, the development of a new process became essential. Therefore, the created process named “Air Rapid Heating Rapid Cooling Sterilization" (ARHRCS) may be an effective solution toward the elimination of microbial filters by causing a rapid and massive temperature increase followed by a fast drop, thus killing any airborne microorganism. 


\section{MATERIAL AND METHODS}

\section{Process simulation and modeling}

The simulation of the air sterilization process (Figure 1) is performed using Aspen HYSYS V10 steady-state process model. The actual simulated design is based on the existing HVAC system in hospitals with some modifications realized to provide him an ability to inactivate harmful microorganisms. ASHRAE standard 170 for healthcare facilities (ASHRAE 2019) was used to select specific operating conditions to simulate a simplified HVAC system in a hospital isolation room (Table 1). Hence, these conditions may vary according to the required room specifications, environmental parameters in addition to the experimental variables regarding microbial inactivation time and temperature. It is important to mention that the actual design can be applied to any other room or the entire hospital if necessary.

Table 1. Operating conditions of the air sterilization process

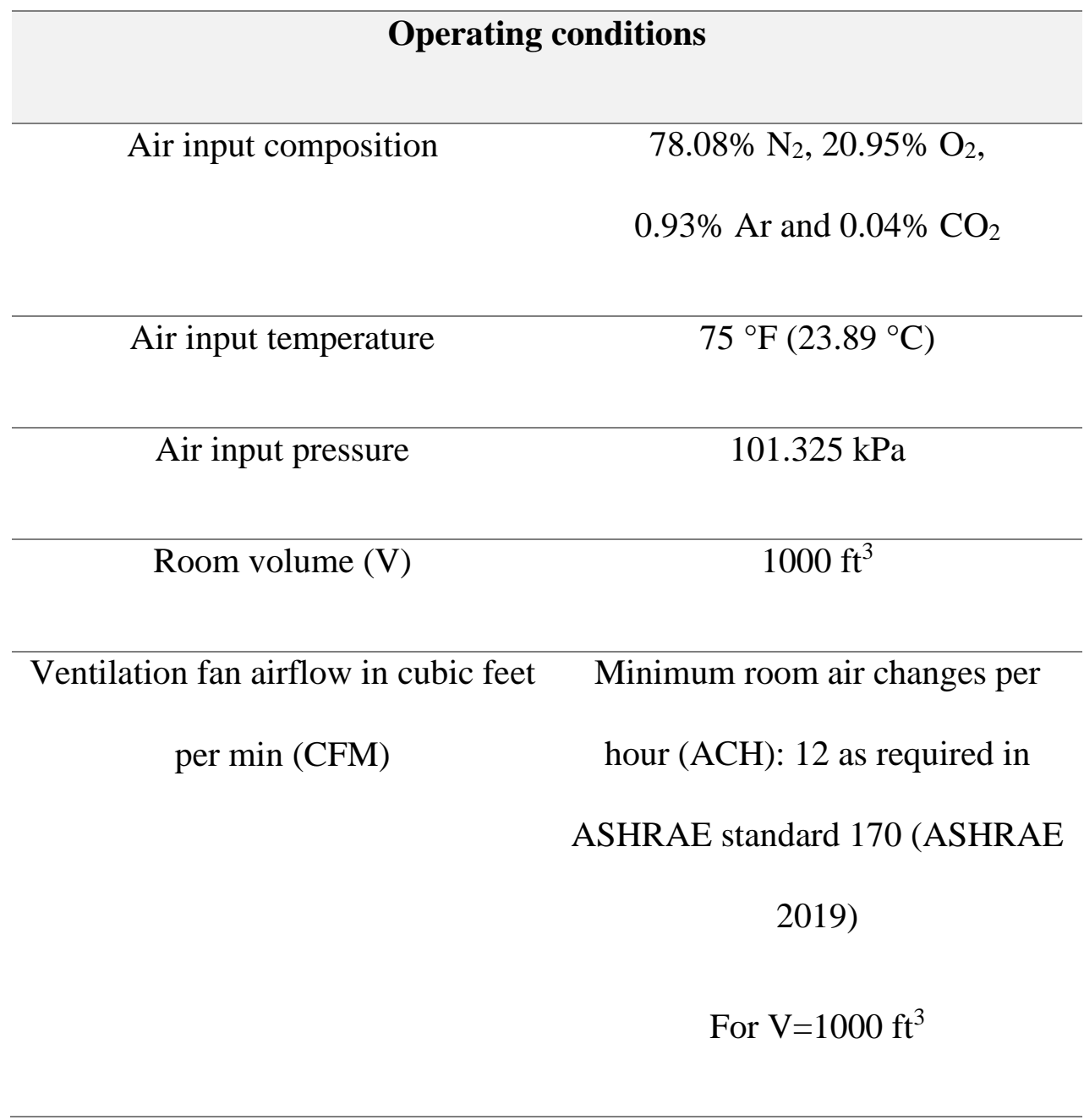




\begin{tabular}{cc}
\hline Chilled water in temperature & $35.6^{\circ} \mathrm{F}\left(2{ }^{\circ} \mathrm{C}\right)$ \\
\hline Chilled water in pressure & $101.325 \mathrm{kPa}$ \\
\hline Expender pressure drop $(\Delta \mathrm{P})$ Other & 0.01 inch of water column $(\mathrm{WC})$ \\
units pressure drop $(\Delta \mathrm{P})$ & 0 (neglected) \\
\hline Fluid package & Peng-Robinson \\
\hline
\end{tabular}

\section{RESULTS AND DISCUSSION}

\section{Simulation of Air Rapid Heating Rapid Cooling Sterilization (ARHRCS) process}

This example simulates the new air sterilization process in airborne infection isolation (AII) room commonly known as negative pressure room is simulated (Figure 1).

The input air enters through a fan where its flow rate is increased to 200 CFM (out 1) before sterilization. Contaminated air is then sent to a heater where its temperature $\left(75^{\circ} \mathrm{F}\right)$ is increased to reach the proposed temperature $\left(302{ }^{\circ} \mathrm{F} ; 150{ }^{\circ} \mathrm{C}\right)$ for microbial inactivation (out 2). The air sterilization step will carry on in a specially designed heating chamber (simulated by a plug flow reactor) by maintaining the high temperature $\left(302^{\circ} \mathrm{F}\right)$ of passing air for a selected time ( 2 sec.) to assure complete sterilization. Later, the clean air (out 3 ) is feed into a heat exchanger where it is immediately cooled to room temperature $\left(75^{\circ} \mathrm{F}\right)$ by using chilled water. Cooling the air using chilled water caused an increase of the water temperature from $35.6{ }^{\circ} \mathrm{F}$ to $75^{\circ} \mathrm{F}$ when using a mass flow rate of $382100 \mathrm{~kg} / \mathrm{h}$ (chilled water in). The use of an indirect refrigeration system based on pumping chilled water is a preferred and safe method according to ASHRAE standard 170 (ASHRAE 2019). The chilled water may be cooled using different thermoelectric cooling solutions or it can be replaced by other approved refrigerants (ASHRAE 2019). An expander was then used to establish a negative pressure room by decreasing the pressure from $101.325 \mathrm{kPa}$ (out 4) to $101.322 \mathrm{kPa}$ (sterilized air exit). To note that the expender should be replaced by a compressor when simulating a positive pressure room, also, it can be removed when no difference of pressure is required in the room. To remove dust and other fine particles, Vacuum Cleaner Filters (VAC) filters are added to the process but they are not part 
of this simulation and do not affect its results. It is worth mentioning a dust filter is needed when the air is entering from the outer environment, in contrast, it is not required for the sterilized exhausted air. The output temperature and airflow are always regulated to maintain a constant flow of clean air and an appropriate room temperature. The moisture level of the sterilized air should be always measured and controlled.

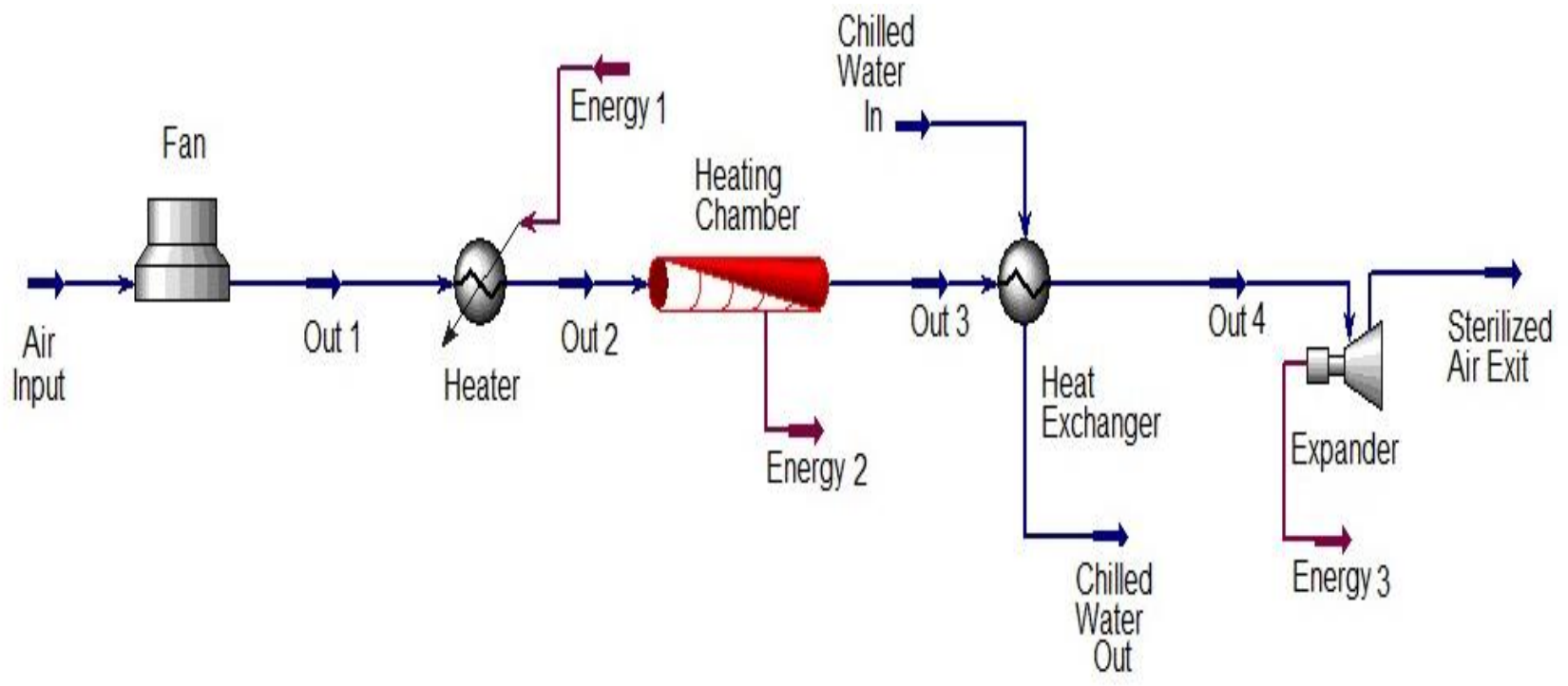

Figure 1. Simulation of the air sterilization process - ARHRCS

The output parameters of this simulation (Table 2) are calculated using the Peng-Robison equation of state.

Table 2. Output parameters of the air sterilization process

\begin{tabular}{l}
\hline \multicolumn{2}{c}{ Output parameters } \\
\hline Sterilized air exit \\
temperature \\
\hline Air output pressure
\end{tabular}

(Negative pressure) 
Output air flow in cubic feet $\quad 200$ CFM

per min

Chilled water out mass flow $\quad 382100 \mathrm{~kg} / \mathrm{h}$

Effect of heated air temperature (out 3) on chilled water in mass flow

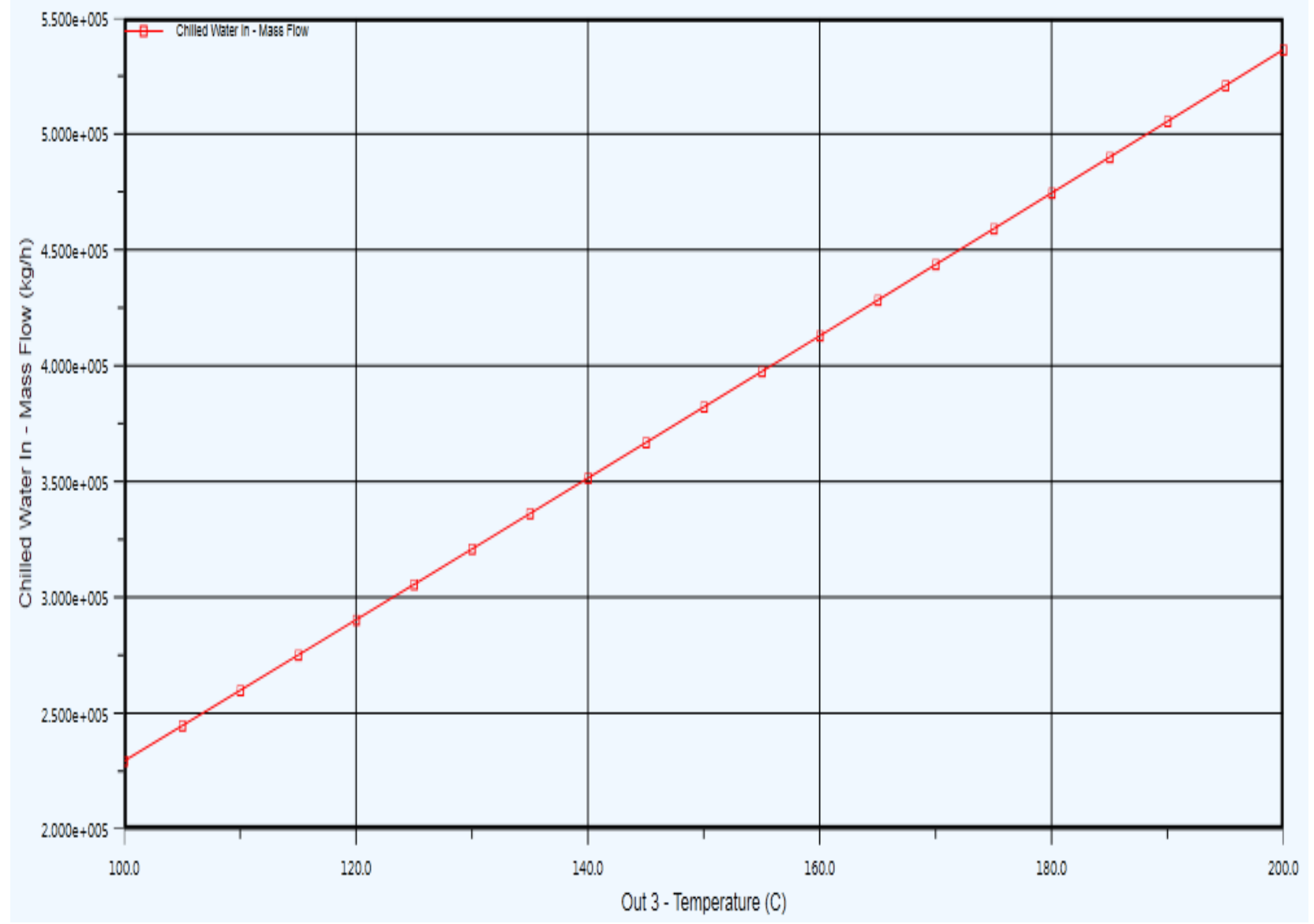

Figure 2. Effect of air sterilizing temperature $\left({ }^{\circ} \mathrm{C}\right)$ on the required water in mass flow

$(\mathrm{kg} / \mathrm{h})$.

For fixed chilled water in temperature of $35.6^{\circ} \mathrm{F}\left(2^{\circ} \mathrm{C}\right)$, increasing the temperature required for microbial inactivation from $100{ }^{\circ} \mathrm{C}\left(212{ }^{\circ} \mathrm{F}\right)$ to $200{ }^{\circ} \mathrm{C}\left(392{ }^{\circ} \mathrm{F}\right)$ resulted in an increase of the chilled water in mass flow from $229500 \mathrm{~kg} / \mathrm{h}$ to $536400 \mathrm{~kg} / \mathrm{h}$ to reach an air output temperature of $75^{\circ} \mathrm{F}\left(23.89{ }^{\circ} \mathrm{C}\right)$. Hence, more heating will increase the chilling and heating costs. For this reason, finding the most suitable heating temperature for microbial inactivation will limit energy consumption.

\section{Head air crown device}


A previous study reported by Xie et al. showed that typically large respiratory droplets containing airborne microorganisms (e.g. SARS-CoV-2) would drop to the surface within a distance of approximately $1 \mathrm{~m}$ during normal breathing (Xie et al. 2007). Sneezing or coughing would highly increase the spread velocity (i.e. $50 \mathrm{~m} / \mathrm{s}$ for sneezing; $10 \mathrm{~m} / \mathrm{s}$ for coughing) compared to breathing $(1 \mathrm{~m} / \mathrm{s}$ ) (Xie et al. 2007). For this reason, generating a laminar flow of air above $1 \mathrm{~m} / \mathrm{s}$ by the air crown device (fixed on the head) will possibly keep HCWs safe from getting infected. The device is plugged using a plastic tube into the HVAC system previously occupied with an airflow control valve with one or more push to connect fitting existent in the hospital room. Thus, the air valve opening leads the previously sterilized air (Figure 1) to flow through the tube and to reach the head air crown device. Laminar airflow is then expelled by the air crown onto the outer side of the plastic face shield worn by the HCWs. An air cooler may be also added to avoid heat discomfort of the HCWs. A fan can be used to increase the exhaust airflow rate to above $1 \mathrm{~m} / \mathrm{s}$. Besides, automated airflow and temperature controllers are crucial for optimal performance.

\section{Potential usages and advantages of the novel air sterilization process}

\section{Customized HVAC system}

It is important to mention that a very limited number of hospital wards are supplied with HEPAfiltered air such as airborne infection isolation (AII) rooms (CDC 2003). These rooms are used to keep infected or susceptible-infected patients away from other patients, and visitors in addition to keeping HCWs in a safe environment. HEPA filters are usually known to be expensive (Cecala et al. 2016), with high maintenance costs (CDC 2003) and need to be periodically replaced upon a decrease of their efficiency (CDC, 2003). These filters are $99.7 \%$ efficient in collecting penetrating particles but their ability to provide adequate protection for all threats is still controversial (McDonald 2020), noting that viruses are smaller in size than the filter pores $(\sim 0.3 \mu \mathrm{m})$ and other factors including temperature, pressure, and humidity may affect its performance (Joubert et al. 2010). Furthermore, the presence of asymptomatic patients such as coronavirus-positive patients or infected HCWs in other units of the hospital and where the air is recirculated without HEPA filtration may result in an environment rich in respiratory viruses and microbes. Thus, leading to an outbreak in the unit and a possible spillover of the infections in the community. Typically, an HVAC system contains cooling and heating coils used to regulate the room temperature (Air 2000). Therefore, customizing the actual system to be able to achieve a high heating temperature in a short period followed by rapid cooling is a key factor for an efficient air sterilization. Hence, the complete elimination of HEPA filter will be possible. Using solar or wind energy to power this process may be a sustainable and costeffective solution. The developed air sterilization process can be used in any of the hospital wards including operating room. Furthermore, an air aspirator can be installed on the upper part of the infected patient bed where it is directly connected to the customized HVAC system. The aspirator in its turn is connected to a disposable transparent plastic vessel covering partially or fully the bed. Accordingly, contaminated air is immediately sterilized and microbial spread is avoided. Depending on its need, the aspirator may be also connected to an aspirating face mask worn by the infected patient. 


\section{Portable air sterilizing unit}

The portable air sterilizing unit is based on the same process previously described. This machine may be used in specific cases where additional air sterilization is needed or even in rooms missing appropriate ventilation where it can be easily moved to. The portable machine may be also connected to the air crown device, aspirating face mask, or to an aspirator fixed above the infected patient bed.

\section{Personal protection of healthcare workers}

It is not easy to control and prevent airborne spread, in addition to the necessity of controlling and maintaining an efficient HVAC system, wearing personalized protective equipment is recommended (Sreeramoju and Cadena 2017). All HCWs entering a negative pressure room should wear an appropriate mask such as N95 respirator. This type of mask is $95 \%$ efficient in filtering out particles sized of $0.3 \mu \mathrm{m}$ or more with less than $10 \%$ leak through facial seal (Kawabe et al. 2004). Breathing in a tight fit N95 mask may be associated with different problems including distress, heat build-up, scars, and pressure ulcer ( $\mathrm{Li}$ et al. 2005). Furthermore, in case more protection is required, HCWs have to use more protective equipment including (N 100, FFP3, etc.) masks, making it harder to complete their work. It is important to mention that due to the pandemic COVID-19, an acute shortage in Personal Protective Equipment (PEEs) has been witnessed (Boškoski et al. 2020). The use of an air crown device plugged into the developed HVAC system with an ability to control the output airflow improves HCWs performance and decreases their risk of getting infected in the healthcare facility (e.g., negative pressure rooms, operating rooms, etc.). Besides, since face shields are mainly used in conjunction with N95 masks, thus having a high flow of laminar air on face shields may provide complete face protection from microbes and limit the usage of extremely protective tight-fitting masks. Furthermore, the possibility of generating cooled air by the air crown device will avoid HCWs heat stress. Other potential usages of this crown may be in the operating room (cardiac surgery, etc.) where a heavy radiation-protective garment is needed, thus by cooling the air a healthy body temperature is maintained. It should be indicated that the head crown device is not heavy to wear since the totality of its functioning units (valves, cooler, controllers, fan, etc.) are fixed into the HVAC system. Furthermore, the crown is made of lightweight plastic material with a well-designed opening for air passage. The mobility of the HCWs wearing the head air crown is limited to the infected room due to the connected air tube length. The easy plug option will help the HCWs to directly reconnect their air crown device to the HVAC system in any hospital wards using the push to connect fitting.

\section{Biosafety cabinets}

Biosafety cabinets are based on decontaminating air by using HEPA filter. Any dysfunction that may cause an airborne leakage through HEPA filter can generate a spread and amplification of this contamination inside the hood or in the outer environment (Laboratory 1989). Therefore, the risk of infection of the laboratory personnel manipulating microbial- 
contaminated samples may increase. Using the above-developed air sterilization process could provide additional benefits to all classes of biosafety cabinets by limiting the risk of any microbial spread.

\section{PATENT}

A patent of this work is to be deposited at the Lebanese Ministry of Economy and Trade.

\section{ACKNOWLEDGMENTS}

We would like to thank the National Council for Scientific Research (CNRS, Lebanon) in collaboration with the research council at Saint-Joseph University (USJ, Lebanon) for funding this project. The first thought of developing a machine/process based on a novel system named "Air Rapid Heating Rapid Cooling Sterilization" (ARHRCS) occurred in March 2020 after receiving in the same month an urgent CNRS-L flash call for COVID-19 management in Lebanon. The project was more elaborated and officially submitted on April 2020 to CNRS-L for funding of the prototype machine.

\section{REFERENCES}

Air indoor. 2000. Impact of ventilation and air cleaning on asthma. National Academies Press (US). https://www.ncbi.nlm.nih.gov/books/NBK224478/ Accessed 4 Aug 2020

ASHRAE: handbook, 2019. https://www.ashrae.org/technical-resources/ashrae-handbook. Accessed 4 Aug 2020

Boškoski, I., Gallo, C., Wallace, M.B., Costamagna, G. 2020. COVID-19 pandemic and personal protective equipment shortage: protective efficacy comparing masks and scientific methods for respirator reuse. Gastrointestinal Endoscopy. https://doi.org/10.1016/j.gie.2020.04.048

CDC: 2003. Guidelines for environmental infection control in health-carefacilities. https://www.cdc.gov/infectioncontrol/guidelines/environmental/background/air.html. Accessed 4 Aug 2020

Cecala, A.B., Organiscak, J.A., Noll, J.D., Zimmer, J.A. 2016. Comparison of MERV 16 and HEPA filters for cab filtration of underground mining equipment. Mineral Engineering, 68:50-58

Fernstrom, A., Goldblatt, M. 2013. Aerobiology and Its Role in the Transmission of Infectious Diseases. Journal of Pathogens. https://doi.org/10.1155/2013/493960

Firquet, S., Beaujard, S., Lobert, P. E., et al 2014.Viruses Contained in Droplets Applied on Warmed Surface Are Rapidly Inactivated. Microbes and Environments, 29:408-412. https://doi.org/10.1264/jsme2.ME14108 
Joubert, A., Laborde, J.C., Bouilloux, L., et al 2010. Influence of Humidity on Clogging of Flat and Pleated HEPA Filters. Aerosol Science and Technology, 44:1065-1076. https://doi.org/10.1080/02786826.2010.510154

Kawabe, Y., Tanaka, S., Nagai, H., et al 2004. Evaluation of quantitative fit-testing of N95 filtering facepiece respirators using Mask-Fitting Tester and improvement of mask fitting by instruction. Kekkaku, 79:443-448.

Laboratory NRC (US) C on HBS in the (1989). Biosafety in Microbiological and Biomedical Laboratories. National Academies Press (US)

Li, Y., Tokura, H., Guo, Y.P., et al 2005. Effects of wearing N95 and surgical facemasks on heart rate, thermal stress and subjective sensations. International Archives of Occupational and Environmental Health, 78:501-509. https://doi.org/10.1007/s00420004-0584-4

McDonald C.J. 2020. Protections against the Risk of Airborne SARS-CoV-2 Infection. mSystems, 5:e00390. https://doi.org/10.1128/mSystems.00390-20

Pastorino, B., Touret, F., Gilles, M., et al 2020. Evaluation of heating and chemical protocols for inactivating SARS-CoV-2. bioRxiv

Sabiiti, W., Azam, K., Esmeraldo, E., et al 2019. Heat Inactivation Renders Sputum Safe and Preserves Mycobacterium tuberculosis RNA for Downstream Molecular Tests. Journal of Clinical Microbiology, 57:e01778.https://doi.org/10.1128/JCM.01778-18

Sreeramoju, P.V. and Cadena, J. 2017. Airborne Precautions and Personal Protective Equipment: The Powered Air-Purifying Respirator-Only Approach. Journal of Infection Prevention, 285-291. https://doi.org/10.1007/978-3-319-60980-5_30

Tang, J.W., Li, Y., Eames, I., et al 2006. Factors involved in the aerosol transmission of infection and control of ventilation in healthcare premises. Journal of Hospital Infection, 64:100-114. https://doi.org/10.1016/j.jhin.2006.05.022

Vijayan, V.K., Paramesh, H., Salvi, S.S., Dalal, A.A.K. 2015. Enhancing indoor air quality The air filter advantage. Lung India, 32:473-479. https://doi.org/10.4103/09702113.164174

Xie, X., Li, Y., Chwang, A.T.Y., et al 2007. How far droplets can move in indoor environments--revisiting the Wells evaporation-falling curve. Indoor Air, 17:211-225. https://doi.org/10.1111/j.1600-0668.2007.00469.x

WHO.2020. Transmission of SARS-CoV-2: implications for infection prevention precautions. https://www.who.int/news-room/commentaries/detail/transmission-of-sars-cov-2implications-for-infection-prevention-precautions. Accessed 4 Aug 2020 